benzoate. Hence the junction of the 5 and $7 \mathrm{mem}$ bered rings in aromadendrene must be the more stable (cis) type. Other features of the stereochemistry of globulol and epi-globulol were also discussed and evidence for the attachment of the cyclopropane ring to $\mathrm{C}_{6}$ and $\mathrm{C}_{7}$ was outlined.

The chemistry of Lunasia alkaloids was discussed by Dr. J. R. Price, who compared the American work on $L$. amara with that done in the Commonwealth Scientific and Industrial Research Organization on $L$. quercifolia. In addition to the tertiary bases, lunacrine and lunacridine, water-soluble bases were present, the major component of which analysed for $\mathrm{C}_{17} \mathrm{H}_{22} \mathrm{O}_{3} \mathrm{~N}^{+}$. A possible structure for this compound, which forms lunacridine when treated with alkali, was presented.
Mr. J. O. Knight presented the final paper in collaboration with A. R. H. Cole, D. C. Shaw and D. E. White, on triterpenoid constitutents of the Myrtaceae. After discussing the common occurrence of betulic acid in members of this family he dealt with the structure of melaleucic acid. The structure originally assigned (3 $\beta$-hydroxylup-20(29)-en-25 : 28 dioic acid; Chem. and Indust., 926 ; 1956) cannot be correct since the lactone which was assumed to involve the 3 -hydroxyl and the 25 -carboxyl affords a tertiary hydroxyl group on reduction with lithium aluminium hydride. The second carboxyl group must be on $\mathrm{C}_{26}$ or $\mathrm{C}_{27}$ and its lactonization involves re-arrangement. Means for distinguishing between these possibilities were discussed.

D. E. White

\title{
THE INSTITUTE OF BIOLOGY ANNUAL CONVERSAZIONE
}

$\mathrm{T}$ HE annual conversazione of the London Branch of the Institute of Biology was held at University College on the evening of July 3. Prof. G. P. Wells and Dr. K. Mellanby (chairman of the London Branch) received members and their guests in the North Cloisters of the College. A large number of exhibits was on display in the Zoology Department, by courtesy of Prof. Wells.

The range of activities of this year's guest Society, the Botanical Society of the British Isles, was well shown by its exhibit. Of particular interest was its progress in the scheme to produce a map of the distribution of British plants. The mass of data for this scheme has been reduced to a minimum of space by the use of a punched-card system, and it is hoped that an atlas of British plants will be produced in 1960. A related project has been undertaken by the British Naturalists' Association, whose exhibit illustrated their work on a phenological survey which will map the changes in the flora and fauna which occur during the year and also the fluctuations of longer period.

Hospital and Laboratory Supplies, Ltd., provided this year's trade-stand, which gave a sample of the comprehensive range of apparatus and materials which this firm can supply. Specimen publications of the Universities Federation for Animal Welfare and of the Institute of Biology were on display, and the Department of Extra-Mural Studies of the University of London had produced an exhibit to illustrate the work of the Department in the field of biology.

Aspects of the Falklands Islands Dependencies Survey biological research were shown, including the method of ageing individual seals by the annual increments of dentine or cementum in the teeth, and also illustrating work on the reproductive cycle of the southern elephant seal. The Ministry of Agriculture, Fisheries and Food provided a stand showing advances in food research and development, particularly in food dehydration, and its Infestation Control Division was represented by Mr. G. A. Brett's exhibit of a common tropical cockroach, Pycnoscelus surinamensis, which is occasionally imported into Britain.

In addition to the exhibits of organizations, a large number of exhibits had been provided by members and guests. Studies on pest control provided the basis of several of these. An example of a serious infestation of a house by the ant Lasius brunneus was found in 1957 (A. A. Green), and there is some evidence of an increased tendency for this ant to invade houses. Population studies of locusts (R. F. Chapman) have made it necessary to be able to separate the egg-pods of locusts from those of other species; various characteristics of the pod can be used. The way in which infestation in a bulk of grain causes heating (D. H. Burges) introduced a model showing the rate of development of colonies of the flat grain beetle (L. P. Lefkovitch), colonies of up to 550,000 individuals being produced in 4 months.

A more gradual example of population increase was shown by the frog Rana ridibunda (J. I. Menzies); 12 specimens were introduced into England in 1935, and their descendents have spread at the expense of the British Rana temporaria and now cover 120 square miles of S.E. England. New anatomical work on the classification of the lugworm genus Arenicola, which can be divided into two groups, was shown by Prof. G. P. Wells, with a map of the zoogeography of this genus. Two very different types of colour change in the Orthoptera were shown (K. H. L. Key), some acridids showing a physiological change from black to blue as a direct reaction to increasing temperature, while some phasmatids show centromorphic colour changes related to population density.

Some exhibits were concerned with genetical studies. Studies on finger-print patterns (S. B. Holt) have shown that the total ridge-count is determined by additive genes with an independent effect but without dominance. In the fungus Aspergillus nidulans (M. Mahoney and D. Wilkie) some spores give rise only to asexual colonies; this appears to be due to the loss of a self-replicating cytoplasmic unit. The rare genetically determined biochemical defect in man known as gargoylism (U. Mittwoch) can be detected by the presence of abnormal inclusions in the lymphocytes.

An exhibit of the different degrees of specificity of both the bacteria and the leguminous plant in their symbiotic relationship (P. S. Nutman) showed also the way in which different mutant strains make it possible to study how the relationship develops. New methods of studying the cellular constituents of yeast (A. A. Eddy) have resulted from the discovery that protoplasts can be prepared by treating yeast cells with certain digestive enzymes of the snail Helix. 
Exhibits concerned with research techniques included the compact lightweight McArthur microscope, designed for field-work ; new uses for cellulose acetate in the culture of anaerobic bacteria and in electrophoresis (W. H. Pierce); and the confining of insects to treated plants under controlled conditions, for use in insecticide screening (D. T. Saggers).
There were many other exhibits, of no less interest and attractiveness than those mentioned above, and the exhibits as a whole provided starting-points for the informal discussion and conversation between those present which are, after all, the prime purpose of a conversazione.

\section{MARIAN SMOLUCHOWSKI}

$\mathrm{M}$ ARIAN SMOLUCHOWSKI, the great Polish theoretical physicist, died during the First World War on September 5, 1917, in Cracow, and a description of his life and work was published by $\mathrm{A}$. Teske three years ago ("Marian Smoluchowski : His Life and Work". Polish State Scientific Publishing House, Cracow, 1955). However, for those not familiar with the Polish language, the brief account of Smoluchowski's career and of his contributions to the theory of probabilities in physics given in the article contributed by $\mathrm{S}$. Ulam to the October number of The American Journal of Physics $(25,475 ; 1957)$ will be very welcome.

Smoluchowski was born in Vienna in 1872. His father was a Cracow lawyer who later became secretary of the Chancellery at the Court of the Emperor Francis Joseph. His mother, too, was well educated, and Smoluchowski was brought up in highly intellectual surroundings. He early showed an interest in science and he studied mathematics and physics at the University of Vienna, attending the lectures given by Boltzmann, Mach and others. He published his first scientific paper in his second year at the University, finally graduating with the highest honours. After a year in Paris working with Lipmann, he studied for a year in Glasgow under Kelvin and then spent a few months in the laboratory of Prof. Warburg in Charlottenberg, finally returning to Vienna to become a lecturer in the University of that city. In 1899 he became a lecturer in Lwow, and the next year, at twenty-eight, he was promoted to a chair of theoretical physies, thus becoming the youngest professor in Austria. In 1913 he was offered, and accepted, the chair of experimental physics at Cracow, but was evacuated to Vienna in the early part of the First World War. The University of Cracow made him rector when he was invited again in 1917 to the chair of theoretical physics in Vienna, but Smoluchowski died suddenly at the age of forty. five before he could deliver his inaugural address entitled "On the Uniformity of Laws of Nature".

Probability theory played an important part in physics during the forty years following Smoluchowski's premature death, and Smoluchowski can claim to have started and anticipated much of the subsequent development. He, together with and independently of Einstein, elaborated and carried forward the ideas of Maxwell and Boltzmann. One of Smoluchowski's mathematical achievements was the clarification of the ergodic hypothesis of Boltzmann and of its place and meaning in statistical mechanics. He realized the difference between the logical structure of the Maxwell and Boltzmann theories and the statistical mechanics of Gibbs. Though primarily a theoretical physicist, Smoluchowski was also very adept in the design and construction of instruments and an extremely good glass-blower. While at Lwow he carried out a brilliant series of experiments confirming Lord Rayleigh's theory that the blue of the sky was caused by the scattering of light. He paid several visits to Great Britain both for mountaineering in Scotland (one of his great passions), and also on academic business. He was an active member of many scientific societies, in particular the Polish Physical Society, of which he became the first president, and he contributed many papers to scientific periodicals, some collections of which have been published since his death.

\section{MENTAL HEALTH RESEARCH FUND}

$\mathrm{O}$ FFICIAL figures show that in 1956 there were in England and Wales more than 204,000 hospital beds occupied by patients suffering from mental illness or mental deficiency. This figure can be com. pared with the 219,000 occupied beds for all other diseases put together. In addition, there were more than 81,000 mental defectives under some sort of supervision provided by the local authority and an unknown number of persons suffering from neuroses which impair their efficiency and happiness. This problem is increasing. In 1949, it led to the formation of the Mental Health Research Fund by a small group of scientists, doctors, and laymen who shared the belief that mental health and mental illness were not receiving that share of attention in research which their importance demands.

The Fund was registered in 1952 and heads of leading research institutions in Great Britain were invited to say in what ways they would wish to use any money that might be available for work in promoting mental health.

A conference at $O x f o r d$ was then convened to which were invited a wide cross-section of scientists, ranging from anatomists to sociologists, as well as a number of practising psychiatrists and professors of psychiatry. Its terms of reference were to answer the following questions: What are the ignorances which to-day principally hamper understanding of the nature, prevention and cure of mental illness? What advances in research are most likely to remove these and so help to reduce the population of mental hospitals and institutions for delinquents?

The Fund has now defined its main purpose and responsibilities as follows: The establishment of research fellowships in the several fields of mental 